\title{
The Role of Early Initiation of Breastfeeding in the Duration of the Third Stage of Delivery and the Amount of Blood Loss in the Fourth Stage in Spontaneous Vaginal Delivery
}

\author{
Sarma Lumbanraja*(i), Wardy Susanto Marpaung, T. M. Ichsan, Ichwanul Adenin (i), Roy Yustin Simanjuntak (i)
}

Department of Obstetrics and Gynecology, Medical Faculty, University of Sumatera Utara, H. Adam Malik General Hospital, Medan, Indonesia

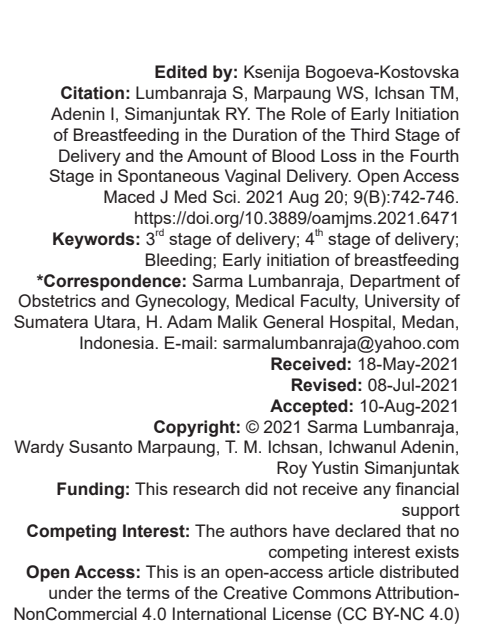

\section{Abstract}

AIM: This study aims to determine the effect of early initiation of breastfeeding (EIBF) in the third stage of labor and the amount of blood loss in the fourth stage of delivery.

METHODS: An experimental study comparing the duration of the $3^{\text {rd }}$ stage and the amount of blood loss in the $4^{\text {th }}$ stage in EIBF, oxytocin administration, and EIBF given oxytocin at spontaneous vaginal delivery in delivery room of H. Adam Malik General Hospital, Dr. Pirngadi Hospital, Sundari Hospital, and Universitas Sumatera Utara Hospita starting from March 2019 until the minimum sample was met.

RESULTS: The data analysis results of the comparison of duration demonstrated $p=0.001$. The comparison among groups with post hoc analysis showed a meaningful comparison in this analysis with $p=0.001$, while duration of the $3^{\text {rd }}$ stage in Group B compared to Group C statistically did not show any significant difference with $p=1.00$. The mean of amount of blood loss among Groups A, B, and C, respectively, was $139 \pm 11.8,141.8 \pm 12.4$, and $132.1 \pm$ 14.4 with $p=0.048$

CONCLUSIONS: It is concluded that the amount of blood loss in the fourth stage among the groups was not significantly different in each group. Comparisons of the amount of bleeding in Group A versus B, A versus C, and B versus $C$ are indicated by the $p$-value of each group, that is, $1.0,0184$, and 0.059 .

\section{Introduction}

According to data from the Ministry of Health of the republic of Indonesia in 2013 , the main factor leading to maternal death during delivery is bleeding by $30 \%$. Postpartum hemorrhage (PPH) can have extensive and bad effects. Not only mothers are at risk of death but also in developing countries, if mothers die, their babies will also be at risk of displacement, and even death [1], [2].

$\mathrm{PPH}$ and severe $\mathrm{PPH}$ are one of the most life-threatening events during delivery and birth, and the prevalence rate is $6 \%$ and $1.86 \%$ of all deliveries, respectively, with varying numbers from various countries [3]. Uterine atony is the most common cause of $\mathrm{PPH}$, which mostly occurs after placenta delivery in the third stage of delivery. PPH increases the risk of hypotension, anemia, blood transfusion, and hemorrhagic shock in postpartum women [4].

The Health Department has addressed maternal mortality through Normal Delivery Care policy in accordance with Making Pregnancy Safer approach initiated by the WHO. This approach aims to reduce maternal mortality rate through activities to improve access to quality maternal health services for pregnant women, maternity, and postpartum women. One of the activities carried out in implementing Normal Delivery Care is early initiation of breastfeeding (EIBF). EIBF program is supported by the government with Government Regulation number 33/2012 article 9 concerning the Provision of Exclusive Breast Milk [5].

\section{Materials and Methods}

It is an experimental study that compares duration of the $3^{\text {rd }}$ stage and the amount blood loss in the fourth stage in the EIBF group, the oxytocin group, and the EIBF group that were given oxytocin in the vaginal spontaneous delivery in $\mathrm{H}$. Adam Malik Medan General Hospital, Dr. Pirngadi Medan, Sundari General Hospital 
Medan, and Universitas Sumatera Utara Hospital from March 2019 until the minimum sample was met. Subjects were all pregnant women who delivered vaginally and met the inclusion and exclusion criteria of this study.

\section{Results}

Table 1 illustrates that the majority of patients in Groups A, B, and C aged 20-35. Group A (initiation of breastfeeding [IBF]) consisted of 19 patients (95\%), Group B consisted of 19 patients (95\%), and Group C consisted of $15(75 \%)$. The following table shows that the age distribution in each group was in the same age range and not significantly different.

Table 1: Age distribution of research subjects

\begin{tabular}{|c|c|c|c|c|c|c|}
\hline \multirow[t]{3}{*}{ Age } & \multicolumn{6}{|c|}{ Group of patient } \\
\hline & \multicolumn{2}{|l|}{ A } & \multicolumn{2}{|l|}{$\mathrm{B}$} & \multicolumn{2}{|l|}{ C } \\
\hline & $\mathrm{n}$ & $\%$ & $\mathrm{n}$ & $\%$ & $\mathrm{n}$ & $\%$ \\
\hline$<20$ years old & 0 & 0 & 1 & 5 & 0 & 0 \\
\hline $20-35$ years old & 19 & 95 & 19 & 95 & 15 & 75 \\
\hline$>35$ years old & 1 & 5 & 0 & 0 & 5 & 25 \\
\hline Total & 20 & 100 & 20 & 100 & 20 & 100 \\
\hline
\end{tabular}

Table 2 illustrates that each group was divided according to gravida, and it was found that the majority of samples in Groups A (IMD), B (Oxytocin), and C (IMD + Oxytocin) were secundigravidas and multigravidas, with 14 each (70\%), 8 (40\%), and 10 (50\%) for secundigravida group and $6(30 \%), 8(40 \%)$, and $9(45 \%)$ in the multigravida group. This shows that the gravida distribution of patients in each group is not different.

Table 2: Gravida distribution of research subjects

\begin{tabular}{|c|c|c|c|c|c|c|}
\hline \multirow[t]{3}{*}{ Gravida } & \multicolumn{6}{|c|}{ Group of patient } \\
\hline & \multicolumn{2}{|l|}{ A } & \multicolumn{2}{|l|}{ B } & \multicolumn{2}{|l|}{ C } \\
\hline & $\mathrm{n}$ & $\%$ & $\mathrm{n}$ & $\%$ & $\mathrm{n}$ & $\%$ \\
\hline Primigravida & 0 & 0 & 3 & 15 & 2 & 10 \\
\hline Secundigravida & 14 & 70 & 8 & 40 & 10 & 50 \\
\hline Multigravida & 6 & 30 & 8 & 40 & 9 & 45 \\
\hline Total & 20 & 100 & 20 & 100 & 20 & 100 \\
\hline
\end{tabular}

Table 3 shows that each group was divided based on upper arm circumference. In each Group A, $B$, and $C$, the majority of patients from each group had an upper arm circumference $>23.5 \mathrm{~cm}$ represented by 18 patients (90\%) in Group A, 20 patients (100\%) in Group B, and 20 patients (100\%) in Group C. This shows that the distribution of samples in each group based on upper arm circumference demonstrated no difference.

Table 3: Distribution of upper arm circumference of research subjects

\begin{tabular}{|c|c|c|c|c|c|c|}
\hline \multirow[t]{3}{*}{ Upper arm circumference $(\mathrm{cm})$} & \multicolumn{6}{|c|}{ Group of patient } \\
\hline & \multicolumn{2}{|l|}{$\mathrm{A}$} & \multicolumn{2}{|l|}{ B } & \multicolumn{2}{|l|}{ C } \\
\hline & $\mathrm{n}$ & $\%$ & $\mathrm{n}$ & $\%$ & $\mathrm{n}$ & $\%$ \\
\hline$\leq 23.5$ & 2 & 10 & 0 & 0 & 0 & 0 \\
\hline$>23.5$ & 18 & 90 & 20 & 100 & 20 & 100 \\
\hline Total & 20 & 100 & 20 & 100 & 20 & 100 \\
\hline
\end{tabular}

Table 4 illustrates the comparison of Stage III duration in each group. The mean of duration obtained among Groups A, B, and C was $16 \pm 0.6$; $4.9 \pm 0.6$; and $4.8 \pm 0.5$, respectively, with $p=0.001$. This shows that the duration of Stage III was different in each group with the shortest duration of the third stage found in the IBF + Oxytocin group.

Table 4: Comparison of duration of the $3^{\text {rd }}$ stage between groups

\begin{tabular}{|c|c|c|c|c|c|c|c|}
\hline Group & $n$ & Mean \pm SD & $p$ & & & & \\
\hline $\operatorname{IBF}(\mathrm{A})$ & 20 & $16 \pm 0.6$ & $0.001^{*}$ & & & & \\
\hline $\begin{array}{l}\text { Oxytocin } \\
\text { (B) }\end{array}$ & 20 & $4.9 \pm 0.6$ & & & & & \\
\hline $\begin{array}{l}\text { IBF + } \\
\text { Oxytocin } \\
\text { (C) }\end{array}$ & 20 & $4.8 \pm 0.5$ & & & & & \\
\hline \multirow[t]{3}{*}{ Variable } & \multicolumn{5}{|c|}{ APGAR score } & $P$ & $\mathrm{R}$ \\
\hline & $5 / 6$ & $6 / 7$ & $7 / 8$ & $8 / 9$ & $9 / 10$ & & \\
\hline & Mean (SD) & Mean (SD) & Mean (SD) & Mean (SD) & Mean (SD) & & \\
\hline S/D ratio & $2.50(0)$ & $2.60(0)$ & $2.72(0.45)$ & $2.77(0.41)$ & $3.21(0.96)$ & 0.068 & 0.253 \\
\hline Lactic acid & $2.7(0)$ & $1.7(0)$ & $2.6(0.5)$ & $2.8(0.4)$ & $2.9(0.5)$ & 0.047 & 0.274 \\
\hline
\end{tabular}

Table 5 shows the comparison of the $3^{\text {rd }}$ stage duration among groups obtained, that is, A was compared to $B, A$ was compared to $C$, and $B$ was compared to $\mathrm{C}$. From the comparison among the groups, it was found that the difference found in $A$ and $B$ was statistically significant. The difference in $A$ and $C$ was also significant with $p=0.001$, while the duration in the $3^{\text {rd }}$ stage in Group B compared to $C$ was not statistically significantly different with $p=1.00$.

Table 5: Post hoc analysis of the duration of the $3^{\text {rd }}$ stage comparison between groups

\begin{tabular}{lllll}
\hline Group & Difference average & Cl 95\% & & $\mathrm{p}^{*}$ \\
\cline { 3 - 4 } & & Min & Max & \\
\hline A versus B & 11.12 & 10.64 & 11.60 & $0.001^{*}$ \\
A versus C & 11.18 & 10.70 & 11.66 & $0.001^{*}$ \\
B versus C & 0.06 & -0.416 & 0.536 & $1.00^{*}$ \\
\hline "Post hoc Bonferroni. & & & &
\end{tabular}

Table 6 illustrates that the mean of amount of blood loss in Groups A, B, and C was $139 \pm 11.8,141.8$ \pm 12.4 , and $132.1 \pm 14.4$, respectively, with $p=0.048$. This shows a significant difference in the amount of blood loss in these three groups.

Table 6: Comparison of the amount of blood loss in the $4^{\text {th }}$ stage between groups

\begin{tabular}{llll}
\hline Group of patient & $\mathrm{n}$ & Mean \pm SD & $\mathrm{p}$ \\
\hline IBF $(\mathrm{A})$ & 20 & $139.8 \pm 11.8$ & $0.048^{*}$ \\
Oxytocin (B) & 20 & $141.8 \pm 12.4$ & \\
IBF + Oxytocin (C) & 20 & $132.1 \pm 14.4$ & \\
\hline$\left(^{*}\right)$ : One-way ANOVA, IBF: Initiation of breastfeeding. & &
\end{tabular}

Table 7 illustrates comparisons among groups of the amount of blood loss in Stage IV using Bonferroni post hoc analysis. It can be seen that the amount of blood loss did not differ significantly in each group after Bonferroni post hoc analysis. Comparison of the amount of blood loss in between Groups $A$ and $B, A$ and $C$, as well as $B$ and $C$ obtained $p$-values in each group $1.0 ; 0.184$; and 0.059 , respectively. These data indicate that administration of oxytocin and EIBF alone did not have significant different results in the amount of blood loss in Stage IV. 
Table 7: Post hoc analysis of comparison of blood loss in the $4^{\text {th }}$ stage among groups

\begin{tabular}{lllll}
\hline Group & Difference average & \multicolumn{2}{l}{ Cl 95\% } & $\mathrm{p}^{*}$ \\
\cline { 3 - 4 } & & Min. & Max. & \\
\hline A versus B & -2.0 & 10.64 & 11.60 & $1.0^{*}$ \\
A versus C & 7.8 & 10.70 & 11.66 & $0.184^{*}$ \\
B versus C & 9.8 & -0.416 & 0.536 & $0.059^{*}$ \\
\hline${ }^{*}$ Post hoc Bonferroni. & & &
\end{tabular}

\section{Discussion}

This study found that the mean of age of most patients was in the range of 20-35 years old in each Group A, B, and C. This result is consistent with the research conducted by Dashtinejad et al., stating that the age of the most consecutive research subjects is in the average ages of $22.9 \pm 3.71$ years old in the EIBF intervention group whereas the average age in the control group (without EIBF) was $23 \pm 4.41$ years old [6]. This is in line with the research conducted by Prishantini et al., which discovers that the highest average in the intervention and control groups is found in the age range of 20-25 years [7]. In this study, patients under 20 years in Groups A and $C$ did not exist, because the selection of samples in this study was random, whereas one case is found at the age of 35 years in Group B and five cases in Group C. This is in accordance with Prishantini's study which finds that the age above 35 years is indeed an age that is not recommended for pregnancy.

In this study, it was found that the average research subjects were second pregnancies in Groups A and C. Meanwhile in Group B, there were as many as multigravida in Group B. This is in line with the research of Prishantini et al. that most groups in both the EIBF and the control groups (without EIBF) are in the multigravida group [7].

Upper arm circumference $>23.5$ in this study was found to be the highest among all groups, indicating that the average nutritional status of the patients was in good condition. This result is in line with the study of Dashtinejad et al. The research subjects in average had good nutritional status [6]. This research was also carried out in Medan which economic level of its population was already good, so this had an impact on improvement of the nutritional status of the study sample, where almost all of them had upper arm circumference $>23.5$.

It was found that the mean of duration of the $3^{\text {rd }}$ stage in Group A was $16 \pm 0.6$ min, Group B was $4.9 \pm 0.6 \mathrm{~min}$, and Group C was $4.8 \pm 0.5 \mathrm{~min}$, with $p=0.001$. This showed that the duration of the third stage was significantly different in each group, with the shortest duration of the $3^{\text {rd }}$ stage found in the IBF + Oxytocin (C) group. Meanwhile, the longest duration of the $3^{\text {rd }}$ stage was found in the oxytocin (A) group.
This is in line with research by Niroomanesh et al. Their results showed that the IBF group had $3^{\text {rd }}$ stage that was much longer than the oxytocin group. The number of pads used in the IBF group was significantly more than the oxytocin group (11.72 vs. 10.58, $p<0.001)$ [3].

Based on Bonferroni post hoc statistical test, the comparison between groups, A compared to $B, A$ compared to $C$, and $B$ compared to $C$ found that the duration of the $3^{\text {rd }}$ stage in Groups $A$ and $B$ was statistically significantly different. Comparison of Group A versus $C$ was also significant in this analysis with $p=0.001$, while duration of the $3^{\text {rd }}$ stage in Group $B$ when compared to $C$ was not statistically significantly different with $p=1.00$. This means that the $3^{\text {rd }}$ stage in Group A (IBF) was indeed inferior compared to the oxytocin (B) group and the oxytocin + IBF (C) group. However, the duration of the $3^{\text {rd }}$ stage in the IBF group was 16 min on average, this condition was still within the time tolerance for the $3^{\text {rd }}$ stage which normally ranged from $<30 \mathrm{~min}$.

Table 6 shows that the mean of the amount of blood loss in the $4^{\text {th }}$ stage among Groups A, B, and C was $139 \pm 11.8,141.8 \pm 12.4$, and $132.1 \pm 14.4$, respectively with $p=0.048$. This indicated a significant difference in the amount of blood loss in these three groups. Based on the post hoc analysis in Table 7, a comparison was made among groups in the amount of blood loss in the $4^{\text {th }}$ stage. From the data above, it was shown that the amount of blood loss did not differ significantly in each group after post hoc analysis. Comparison of the amount of blood loss in Groups A and B, A and C, and $B$ and $C$ obtained $p$ values in each group 1.0; 0.184 ; and 0.059 , respectively. The data demonstrated that the administration of oxytocin or IBF alone did not give significant different results in the amount of blood loss in the $4^{\text {th }}$ stage.

Bullough et al. conducted research on three groups of women. The first group performed nipple stimulation for $15 \mathrm{~min}$, the second group received syntometrine injection, and the other group received expectative management in the $3^{\text {rd }}$ stage. The results showed that the syntometrine group had the least amount of blood loss (on average of $83 \mathrm{~mL}$ ) compared to nipple stimulation (on average of $166 \mathrm{~mL}$ ) and the expectative management group (on average of $257 \mathrm{~mL}$ ) [8]. Their results are not in accordance with the results of this study, because this study found that the IBF group and the oxytocin group did not show any significant difference in the amount of blood loss in Stage IV. The reason for this difference may be caused by the small number of the samples compared to the study by Bullough et al. A study by Narenji et al., which involved three groups of women $(n=150)$, assessed the effect of breastfeeding on the duration of the $3^{\text {rd }}$ stage of delivery and $\mathrm{PPH}$. One group received $10 \mathrm{IU}$ of oxytocin IM soon after the baby was born $(n=50)$, one group began breastfeeding immediately after the baby was born $(n=50)$, and another group did not receive any 
intervention $(n=50)$. Their results showed that although the average blood loss volume in the expected group was higher compared to the other two groups, there were no significant differences among the three groups in terms of longer $3^{\text {rd }}$ stage and PPH [9].

During the research process, it was demonstrated that most mothers in the IBF group were satisfied and happy with the intervention. Moreover, the number of breastfeeding in the first $24 \mathrm{~h}$ after giving birth in the IBF group was higher compared to the oxytocin group. Mothers in the IBF group complained of less severe pain after giving birth in the first $24 \mathrm{~h}$ after delivery. The research has shown that nipple stimulation or IBF caused oxytocin secretion in pulsatile form, for 3-4 times in the bloodstream every 5-15 min [10]. Studies have shown that endogenous oxytocin could reduce stress, support emotional and mental well-being, and improve bonding between mother and newborn [11], [12]. Wiklund in research compared two groups of women receiving exogenous oxytocin for augmentation and women who did not get oxytocin. This study found that groups that received exogenous oxytocin were 3 times less likely to breastfeed their babies during the first $4 \mathrm{~h}$ after giving birth [13]. This was due to the administration of exogenous oxytocin which could interfere with endogenous oxytocin secretion and could delay the release of milk and prevent exclusive breastfeeding [14].

Limitations of this study were that pumps were not used to stimulate the breast to achieve targeted stimulation, so the strength of the IBF varied in each sample, then, the sample in our study was not many, other than that we did not measure endogenous oxytocin levels in the division of pregnant women which might make the results more objective.

\section{Conclusions}

The majority of patients in Groups A, B, and C aged 20-35 with 19 (95\%), 19 (95\%), and 15 (75\%) patients, respectively. Based on gravida, it was found that the majority of samples in Groups A, B, and C were secundigravida with $14(70 \%), 8(40 \%)$, and $10(50 \%)$, respectively. Based on MUAC in each group, the majority of patients in $A, B$, and $C$ had MUAC $\geq 23.5$ with 18 patients (90\%), 20 patients (100\%), and 20 patients $(100 \%)$, respectively. The comparison of the duration of Stage III in each group obtained the mean of the duration among Groups $A, B$, and $C$, that is, $16 \pm 0.6 ; 4.9 \pm 0.6$; and $4.8 \pm 0.5$, respectively, with $p=0.001$. This indicated that the duration of Stage III was different in each group with the shortest time found in Group C. From the comparison among groups using post hoc analysis, it was found that the ratio of $A$ and $B$ and $A$ and $C$ was a significant different in this analysis with $p=0.001$; meanwhile, duration of the third stage in Group B compared to C did not differ statistically significantly with $p=1.00$. The mean amount of blood loss among Groups A, B, and C was $139 \pm 11.8,141.8 \pm$ 12.4 , and $132.1 \pm 14.4$, respectively, with $p=0.048$. This indicated significant differences in the amount of blood loss in these three groups. Comparison among groups of the amount of blood loss in the fourth stage when using post hoc analysis could be concluded that the amount of blood loss did not differ significantly in each group. Comparison of the amount of bleeding in Groups $A$ and $B, A$ and $C$, and $B$ and $C$ found the value of $p$ in each group, namely, $1.0 ; 0.184$; and 0.059 , respectively. It was concluded that administration of oxytocin and IBF alone did not give any significantly different results in the amount of blood loss in the fourth stage.

\section{Acknowledgment}

This research was conducted by author herself.

\section{References}

1. Kementerian Kesehatan RI. Profil Kesehatan. Indonesian: Kementerian Kesehatan RI; 2016. https://doi.org/10.24252/bio. v5i1.3429

2. Main EK, Goffman D, Scavone BM, Low LK, Bingham D, Fontaine PL, et al. National partnership for maternal safety: Consensus bundle on obstetric hemorrhage. Obstet Gynecol. 2015;126(1):155-62. https://doi.org/10.1111/jmwh.12345

PMid:26241269

3. Niroomanesh S, Chitsaz F, Babai G. Comparison of oxytocin and sucking on length of the third stage of labor and first day haemorrhage. Tehran Univ Med J. 1998;56(2):67-71

4. Perkumpulan Obstetri dan Ginekologi Indonesia Himpunan Kedokteran Feto Maternal. Pedoman Nasional Pelayanan Kedokteran: Perdarahan Pasca Salin; 2016.

5. Lumbanraja SN. ASI dan Aspek Klinisnya; 2015.

6. Dashtinejad E, Abedi P, Afshari P. Comparison of the effect of breast pump stimulation and oxytocin administration on the length of the third stage of labor, postpartum hemorrhage, and anemia: A randomized controlled trial. BMC Pregnancy Childbirth. 2018;18(1):293. https://doi.org/10.1186/s12884-018-1832-z PMid:29981576

7. Anto AP, Dash M. Early initiation of breastfeeding on outcome of third stage of labour among the intra-natal mothers at Rggw and Ch, Puducherry. Acta Sci Paediatr. 2018;1(2):9-16. Available from: https://www.actascientific.com/aspe/pdf/aspe01-0009.pdf. [Last accessed on 2021 Jan 15].

8. Bullough $\mathrm{CHW}$, Msuku RS, Karonde L. Early suckling and postpartum haemorrhage: Controlled trial in deliveries by traditional birth attendants. Lancet. 1989;2:522-5. https://doi. org/10.1016/s0140-6736(89)90652-1

PMid:2570234

9. Narenji F, Bahmani Z, Mirzaeie R. Comparison of the effect of oxytocin IM injection and nipple stimulation on bleeding and length of third stage of delivery. CMJA. 2012;2(1):119-25. 
10. Israel JM, Poulain DA, Oliet SH. Oxytocin-induced postinhibitory rebound firing facilitates bursting activity in oxytocin neurons. J Neurosci. 2008;28(2):385-94. https://doi.org/10.1523/ jneurosci.5198-07.2008

PMid:18184781

11. Neumann ID, Landgraf R. Balance of brain oxytocin and vasopressin: Implications for anxiety, depression, and social behaviors. Trends Neurosci. 2012;35(11):649-59. https://doi. org/10.1016/j.tins.2012.08.004

PMid:22974560

12. Lumbanraja SN. Exclusive breastfeeding able to reduce the development of childhood asthma. Asian J Pharm Clin Res. 2017;10(9):314-7. https://doi.org/10.22159/ajpcr.2017. v10i9.15118

13. Wiklund I, Norman M, Uvnäs-Moberg $K$, Ransjö-Arvidson $A B$, Andolf E. Epidural analgesia: Breast-feeding success and related factors. Midwifery. 2009;25(2):e31-8. https://doi. org/10.1016/j.midw.2007.07.005

PMid:17980469

14. Jonas $W$, Johansson LM, Nissen E, Ejdebäck M, RansjöArvidson $A B$, Uvnäs-Moberg K. Effects of intrapartum oxytocin administration and epidural analgesia on the concentration of plasma oxytocin and prolactin, in response to suckling during the second day postpartum. Breastfeed Med. 2009;4(2):71-82. https://doi.org/10.1089/bfm.2008.0002

PMid:19210132 